\title{
Komunikasi Eksternal Marketing Public Relations dalam Membangun Citra Positif Perusahaan (Studi Kasus pada PT Sasa Inti)
}

\author{
Aurelia Thomas, Roswita Oktavianti \\ aureliaathomas@gmail.com,roswitao@fikom.untar.ac.id \\ Fakultas Ilmu Komunikasi Universitas Tarumanagara
}

\begin{abstract}
Public Relations contributes to the marketing efforts of a company in fostering external relations. MPR is needed to become a bridge between product sales and the creation of a corporate image. In this research, the researcher tries to explain more deeply about how MPR external communication carried out by one of the fast-moving consumer good (FMCG) companies, namely PT Sasa Inti, in building a positive image. This study aims to see how MPR's external communication practices in building a positive image of the company through several forms of communication, programs, strategies and techniques that are able to support in influencing the public as well as realizing consumer loyalty. This research uses a qualitative approach with a case study method. The case study was conducted at PT Sasa Inti Jakarta. Data collection was carried out by interviewing techniques which were conducted face-to-face by applying the Covid-19 health protocol, observation, namely nonparticipant observation through a website visit and documentation in the form of photo awards obtained by this company. The MPR external communication carried out by PT Sasa Inti in building a positive image occurs reciprocally, namely communicating from the organization to the audience and vice versa, such as dealing with customers, communities and government.
\end{abstract}

Keywords: external communication, marketing public relations, positive company image

\begin{abstract}
Abstrak
Public Relations berkontribusi dalam upaya marketing sebuah perusahaan dalam membina hubungan eksternal. Marketing Public Relations (MPR) Sangat dibutuhkan untuk menjadi jembatan antara penjualan produk dan penciptaan citra perusahaan. Di dalam penelitian ini, peneliti berusaha menjelaskan lebih dalam mengenai bagaimana komunikasi eksternal $M P R$ yang dilakukan salah satu perusahaan barang konsumen yang bergerak cepat atau fast moving consumer good (FMCG) yaitu PT Sasa Inti dalam membangun citra positif. Penelitian ini bertujuan untuk melihat bagaimana praktik-praktik komunikasi eksternal $M P R$ dalam membangun citra positif perusahaan melalui beberapa bentuk komunikasi, program, strategi maupun teknik yang mampu mendukung dalam mempengaruhi publik sekaligus mewujudkan loyalitas konsumen. Penelitian ini menggunakan pendekatan kualitatif dengan metode studi kasus. Studi kasus dilakukan pada PT Sasa Inti Jakarta. Pengumpulan data dilakukan dengan teknik wawancara yang dilakukan secara tatap muka dengan menerapkan protokol kesehatan Covid-19, observasi yaitu non-participant observation melalui website visit dan dokumentasi berupa foto penghargaan yang didapat oleh perusahaan ini. Komunikasi eksternal $M P R$ yang dilakukan PT Sasa Inti dalam membangun citra positif terjadi secara timbal balik yaitu berkomunikasi dari organisasi kepada khalayak dan sebaliknya, seperti berhubungan dengan pelanggan, komunitas dan pemerintah.
\end{abstract}

Kata Kunci: citra positif perusahaan, komunikasi eksternal, marketing public relations 
Aurelia Thomas, Roswita Oktavianti: Komunikasi Eksternal Marketing Public Relations dalam Membangun Citra Positif Perusahaan (Studi Kasus pada PT Sasa Inti)

\section{Pendahuluan}

Keadaan pandemi Coronavirus Disease 2019 (Covid-19) membuat perekonomian di Indonesia menjadi krisis (kompas.com, 2020), hal ini menuntut perusahaan secara tidak langsung untuk lebih meningkatkan kinerja dan daya saing untuk bertahan dalam iklim usaha yang kurang kondusif. Salah satu cara yang dapat ditempuh adalah dengan memaksimalkan setiap potensi dalam meningkatkan komunikasi yang lebih optimal antara perusahaan sebagai komunikator dan publik di luar perusahaan sebagai komunikasinya melalui perantaraan public relations (PR).

Saat pandemi seperti ini, para praktisi $P R$ diberikan tantangan untuk lebih memahami lebih dalam bahwa $P R$ sebagai organisasi penting yang memiliki fungsi sosial. Menurut Harris, $P R$ dalam suatu organisasi seringkali disebut sebagai Corporate Public Relations (CPR). Menurut Joep Cornelissen, sejak tahun 1990 hingga sekarang fungsi $P R$ dan marketing diintegrasikan ke dalam konsep Corporate Public Relations (CPR). Peran $C P R$ adalah lembaga yang menjalankan fungsi $P R$ yang sangat diperlukan karena dalam kegiatan $C P R$ ini lebih menekankan kepada pembentukan citra perusahaan baik secara internal dan eksternal. Untuk membentuk citra tersebut, terdapat proses yang dilakukan oleh $M P R$ yaitu menjaga pangsa pasar serta produknya.

Menurut Thomas L. Harris, menyatakan bahwa MPR adalah proses perencanaan, pelaksanaan, dan evaluasi program yang mendorong pembelian dan kepuasan konsumen melalui informasi dan kesan yang mengidentifikasi perusahaan dan produknya berdasarkan kebutuhan, keinginan, perhatian, dan minat konsumen (Maryam, 2017). Komunikasi eksternal terdiri dari jalur secara timbal balik yaitu yang pertama komunikasi dari organisasi kepada khalayak. Komunikasi ini bersifat informatif, sehingga khalayak merasa memiliki keterlibatan. Komunikasi ini dapat terjadi melalui berbagai bentuk, seperti majalah organisasi, press release, pidato, radio, film dokumenter, brosur, poster dan konferensi pers. Lalu yang kedua, komunikasi dari khalayak kepada organisasi. Komunikasi ini merupakan umpan balik sebagai efek dari kegiatan dan komunikasi yang dilakukan oleh organisasi (Pradnyana dan Sriwahyuni, 2014).

Dengan hal ini, $M P R$ sangat dibutuhkan untuk menjadi jembatan antara penjualan produk dan penciptaan citra perusahaan. $M P R$ sendiri dapat dibedakan antara seorang marketing yang lebih berorientasi ke laba, sedangkan seorang $P R$ lebih ke persiapan dan penyebaran komunikasi. Namun, perbedaan ini telah diterapkan oleh $M P R$ yang secara langsung mendukung promosi perusahaan atau produk serta pembentukan citra positif perusahaan (Suwatno, 2018).

$P R$ berperan dalam setiap keputusan strategis perusahaan baik itu dalam kinerja maupun peningkatan kualitas kinerja bagian pemasaran yang terus melakukan perbaikan sehingga menghasilkan kualitas yang tinggi. Konsep dari $P R$ sendiri adalah memberikan kontribusi kepada upaya marketing dengan cara menjaga lingkungan eksternal dan membina saling pengertian diantara kedua belah pihak. Oleh karena itu, penelitian ini dilakukan dengan mengangkat judul "Komunikasi Eksternal Marketing Public Relations Dalam Membangun Citra Positif Perusahaan" (Studi pada PT Sasa Inti). Rumusan masalah dalam penelitian ini adalah bagaimana komunikasi eksternal marketing public relations PT Sasa Inti dalam membangun citra positif perusahaan? 


\section{Metode Penelitian}

Peneliti menggunakan pendekatan penelitian kualitatif karena penelitian tersebut telah sesuai dengan tujuan penelitian ini, yaitu ingin mengetahui cara membangun komunikasi eksternal yang dilakukan oleh marketing public relations PT Sasa Inti dalam membangun citra positif perusahaan. Penelitian ini difokuskan pada PT Sasa Inti. Pada penelitian ini, subyek penelitian adalah Divisi Brand \& Marketing Communication dari PT Sasa Inti yang berada di divisi brand communication. Sedangkan obyek penelitian adalah komunikasi eksternal marketing public relations perusahaan tersebut.

Pengumpulan data dalam penelitian ini dilakukan pengumpulan data primer dan data sekunder. Data primer dilakukan dengan mengambil informasi dari hasil wawancara dan cara non-participant observation. Adapun narasumbernya yaitu Albert Dinata selaku General Manager Marketing dari PT Sasa Inti dan Rida Atmiyanti selaku Corporate Communication Manager dari PT Sasa Inti. Wawancara yang dilakukan peneliti secara tatap muka, namun waktu yang disediakan oleh pihak perusahaan telah ditentukan yaitu maksimal 3 jam dalam sehari dengan tetap mengikuti protokol kesehatan karena pandemi Covid-19. Sedangkan data sekunder dilakukan dengan mengambil dokumen-dokumen yang berkaitan dengan penelitian ini.

Pada penelitian ini, penulis mengukur keabsahan data dengan menggunakan teknik triangulasi data dengan membandingkan hasil observasi yang dilakukan oleh peneliti yaitu non-participant observation melalui website visit dengan data yang telah dikumpulkan yaitu hasil wawancara dengan narasumber yaitu semua pihak terkait, baik itu primer (pihak yang menjadi fokus utama dalam wawancara), maupun sekunder (pihak yang menjadi fokus pelengkap dalam wawancara).

\section{Hasil Temuan dan Diskusi}

\section{Hubungan dengan Pelanggan}

Pelanggan adalah pusat kegiatan bisnis dan merupakan penentu akhir kesuksesan sebuah perusahaan. Setiap perusahaan harus menyadari bahwa hubungan dengan pelanggan merupakan aktivitas perusahaan yang paling vital. Apapun yang dilakukan oleh perusahaan adalah dalam rangka memenuhi kepentingan dan kepuasan pelanggan. Pelanggan adalah tujuan diadakannya aktivitas bisnis (Suwatno, 2018).

Perusahaan PT Sasa Inti selalu bergerak maju sesuai dengan value CARE (Courage Action Oriented Respectful Enthusiatic) yang percaya akan membawa perusahaan ini menjadi yang terbaik. Perusahaan ini menggunakan teknik komunikasi yang selalu berinovasi terhadap produk yang dibuat, selain itu juga melakukan kegiatan-kegiatan positif dan bersifat komersial dan non-komersial, baik itu mencakup penjualan maupun prestasi yang diperoleh, seperti kegiatan sosial yang ingin berdampak ke masyarakat.

Oleh karena perusahaan ini selalu ingin berdampak di mata masyarakat, perusahaan $F M C G$ ini memenuhi bentuk praktik $M P R$, dimulai dari publikasi yang dilakukan melalui Point of Sale Material (POS Material), seperti poster. Perusahaan ini juga memperhatikan media identitasnya, seperti logo yang selalu direjuvinasi agar tidak terlihat kuno. Lalu, PT Sasa Inti juga selalu ingin terlihat berbeda dan selalu muda dari kompetitor, yaitu saat peluncuran kampanye monosodium glutamate 
Aurelia Thomas, Roswita Oktavianti: Komunikasi Eksternal Marketing Public Relations dalam Membangun Citra Positif Perusahaan (Studi Kasus pada PT Sasa Inti)

$(M S G)$. PT Sasa Inti menggandeng anak-anak muda dan membuat iklan baru di kota New York. Hal ini dikarenakan ketika melihat sensus penduduk yaitu 250 juta orang, terdapat $80 \%$ generasi milenial di dalamnya, dengan beralasan generasi milenial tersebut sebentar lagi akan berkeluarga. Oleh karena itu perusahaan FMCG ini menggunakan objek-objek yang berjiwa muda, agar relevan ke generasi milenial. Hal ini disampaikan oleh informan 2, Albert Dinata:

"Publikasi disini kayak poster, terus kita bikin juga billboard.lalu, melalui media identitas ya, seperti logo kan, logo kita udah ganti, kalau yang lama ada garis, warnanya biru, sekarang kan kita ganti merah, karena makanan itu cocoknya warna merah, kegiatan di divisi kita juga mengadakan acara untuk menarik perhatian baru, seperti konser live, isyana awal tahun 2020, pertama kali. Launching campaign MSG generasi micin. Bikin iklan baru di New York. Ini kita bikin iklannya milenial, kenapa milenial? Karena kalau dilihat dari sensus penduduk 250 juta, itu milenial 80\% milenial, kan milenial bentar lagi akan berkeluarga, nah jangan sampai, kalau komunikasi nya tua semua, nanti gaktau sasa, makanya salah satu objeknya campaign-campaign kita muda semua. Supaya bisa relevan ke generasi milenial." -Albert Dinata

Dalam hal meluncurkan produk, perusahaan ini menggunakan teknik kampanye 360degree, yang dijalankan dari tingkat atas yaitu televisi sampai ke tingkat bawah yaitu low-key market, ketika perusahaan ingin meluncurkan produk, hal ini dilihat berdasarkan seberapa banyak channel yang digunakan oleh konsumen. Selain itu juga, PT Sasa Inti juga ingin membuat kesadaran konsumen terhadap produk yang dihasilkan. Salah satu contohnya, dengan adanya isu MSG membuat orang bodoh, PT Sasa Inti ingin membenarkan bahwa opini tersebut tidak benar. PT Sasa Inti selalu menerapkan culture CARE dalam setiap meluncurkan produk bahwa sudah tersertifikasi badan pengawas obat dan makanan (BPOM), halal dan berstandar organisasi internasional untuk standardisasi (ISO). Hal ini bertujuan untuk membangun kepercayaan konsumen. Untuk memberikan edukasi, perusahaan ini selalu mendorong sales force seperti majalah dan iklan, baik itu soft selling dan hard selling. Hal ini disampaikan oleh informan 1, Rida Atmiyanti:

"Jadi kita setiap launching plan gitu, kita selalu 360degree marketing campaign, dari mulai di atas, tv sampai ke bawah di low-key market. semua channel konsumen lihat dimana, kita jalanin. Sekarang kan marketing 4.0, konsumen mau apa kita bikin." -Rida Atmiyanti

\section{Hubungan dengan Komunitas}

Komunitas adalah sekelompok orang dalam ruang kepentingan yang sama. Cultif dan Center mengatakan bahwa kesejahteraan itu penting dalam rangka menjalankan hubungan yang baik dengan komunitas. Cultif dan Center menjelaskan lebih jauh terkait sebelas kesejahteraan bagi komunitas yaitu kesejahteraan komersial, dukungan agama, lapangan pekerjaan, fasilitas pendidikan, hukum, ketertiban, keamanan, pertumbuhan penduduk, perumahan, perhatian terhadap keselamatan umum, penanganan kesehatan yang progresif dan pemerintah ketataprajaan yang cakap.

Dalam menjalin kerjasama dengan pihak eksternal, PT Sasa Inti menjalani banyak program yaitu Corporate Social Responsibility (CSR). Selain event-event, aktivitas MPR disini menjalani kegiatan CSR, dapat dibilang bahwa CSR di perusahaan ini sudah sangat terstruktur, aktivitas yang dilakukan berupa membagikan lunch box, memberi bantuan alat pelindung diri (APD) dan makanan- 
makanan, memberikan edukasi tentang kebersihan dengan menggandeng anak-anak kedokteran. Selain itu perusahaan ini mengadakan edukasi tentang kebersihan di media. Lalu aktivitas ini akan dibagikan melaluicwebsite resmi perusahaan ini. Hal ini disampaikan oleh informan 1, Rida Atmiyanti:

"Biasanya aktivitas ruang lingkup kita itu kebanyakkan CSR, bisa dibilang bahwa CSR kita sudah terstruktur, seperti pandemi ini, kita membagikan lunch box, support APD, karena kita industry makanan, jadi kita lebih banyak support makanan. Kita juga ada edukasi tentang kebersihan di masa pandemi, selain itu, kita juga menggandeng anak-anak dari kedokteran." -Rida Atmiyanti

Perusahaan ini selalu menggandeng orang ketiga untuk bekerjasama, menggandeng kampus dan lembaga-lembaga sosial. Lalu perusahaan ini membentuk beberapa komunitas seperti komunitas cooking class, komunitas PKK, komunitas sepeda. Hal ini memudahkan perusahaan untuk membagikan berita-berita baru menjadi luas.

Dengan terlihat unik dan berbeda agar relevan dengan generasi milenial seperti ini, PT Sasa Inti sering kali diwawancarai oleh majalah. Untuk sponsor sendiri, perusahaan ini menerima minimal 2-3 acara, dan kegiatan tersebut sebagian besar acara televisi. PT Sasa Inti pernah mensponsori acara Opera Van Java yang ditayangkan di stasiun televisi Trans TV dengan menempatkan brand SASA. Selain itu juga, perusahaan ini bekerjasama dengan kedokteran gizi sebagai sponsor.

\section{Hubungan dengan Pemerintah}

Dalam sebuah organisasi, $P R$ sebagai seorang staf ahli yang menangani peraturan-peraturan pemerintah yang sangat berkaitan dengan organisasi. Tugas mereka seperti menguasai peraturan-peraturan yang dikeluarkan pemerintah dalam rangka mencegah terjadinya kegiatan organisasi yang bertentangan dengan kebijaksanaan pemerintah dan membina hubungan dengan instansi pemerintah.

Dengan menjadi perusahaan FMCG ternama di Indonesia, pasti sering untuk bekerjasama dengan pemerintah. PT Sasa Inti selalu mendukung setiap kegiatan sosial yang dilakukan oleh pemerintah seperti program stanting dengan kementerian kesehatan, serta membantu menangani Covid-19 saat ini. Uniknya, PT Sasa Inti tidak pernah bertentangan dengan pemerintah dan tidak pernah melanggar peraturan yang telah ditetapkan oleh pemerintah. Hal ini dapat dinamakan sebagai prestasi. Oeh karena itu di saat pandemi Covid-19, pemerintah memberi subsidi jahe untuk seluruh karyawan di perusahaan ini dan memberikan layanan serology test setiap sebulan sekali. Hal ini disampaikan oleh informan 2, Albert Dinata:

"Kita selama ini selalu support, seperti CSR kan sebagai bentuk tanggung jawab sosial Sasa ke masyarakat. Seperti saat pandemi sekarang kan, pemerintah subsidi jahe untuk seluruh karyawan Sasa agar tetap sehat terus, lalu memberikan layanan serology test untuk karyawan Sasa." - Albert Dinata

\section{Citra Positif}

Menurut Sutisna, citra itu penting karena citra dapat menceritakan harapan Bersama kampanye pemasaran eksternal, sebagai penyaring yang mempengaruhi persepsi pada kegiatan perusahaan, sebagai fungsi dari pengalaman dan harapan konsumen atas kualitas pelayanan perusahaan, serta mempunyai pengaruh penting terhadap manajemen atau berdampak pada internal.

Dari kegiatan MPR yang dilakukan, PT Sasa Inti ingin menanamkan kepercayaan kepada konsumen, karyawan maupun stakeholder melalui kegiatan- 
Aurelia Thomas, Roswita Oktavianti: Komunikasi Eksternal Marketing Public Relations dalam Membangun Citra Positif Perusahaan (Studi Kasus pada PT Sasa Inti)

kegiatan yang positif, salah satunya kegiatan Corporate Social Responsibility (CSR). Kegiatan ini dapat dikatakan sebagai sebuah cerminan kinerja perusahaan yang dipresentasikan kepada pihak luar, yaitu nantinya kegiatan ini diberitakan ke televisi seperti grup MNC, RCTI, komunitas-komunitas yang dibuat, sehingga dapat menghasilkan citra positif di mata masyarakat. PT Sasa Inti ingin selalu menjaga hubungan dengan pelanggan, komunitas dan pemerintah agar semua kinerja di perusahaan dapat berjalan dengan lancar dan memberikan dampak yang positif juga untuk citra perusahaan. Hal ini disampaikan oleh informan 2, Albert Dinata:

"Penting banget. Kalau citra jelek, orang gakmau pakai Sasa lagi. Jadi di perusahaan ini tentunya harus membuat manajemen yang terstruktur. Gunanya untuk apa? Agar kinerja di perusahaan selalu berjalan dengan lancer dan hal itu memberikan dampak yang positif untuk citra perusahaan." -Albert Dinata

Hal ini juga disampaikan oleh informan 1, Rida Atmiyanti bahwa citra itu sangat berpengaruh penting terhadap perkembangan perusahaan:

"Citra itu sangat penting, karena bisa membuat image perusahaan menjadi semakin kuat, pentingnya pengaruh citra terhadap perkembangan citra perusahaan akan berpengaruh kepada brand image, nah brand image ini akan berpengaruh terhadap kemauan orang untuk membeli produk pastinya. Pada intinya kita menanamkan kepercayaan ke konsumen, memberikan kepercayaan untuk karyawan juga, stakeholder juga. Kalau hasilnya positif, pasti menghasilkan pandangan yang positifjuga kan." -Rida Atmiyanti

\section{Simpulan}

Komunikasi eksternal $M P R$ yang dilakukan salah satu perusahaan barang konsumen yang bergerak cepat atau fast moving consumer good (FMCG) yaitu PT Sasa Inti dalam membangun citra positif terdiri dari jalur secara timbal balik yaitu komunikasi dari organisasi kepada khalayak dan sebaliknya. Khalayak eksternal ini biasanya berhubungan dengan pelanggan, komunitas dan pemerintah.

Pertama, berhubungan dengan pelanggan. Dalam meluncurkan produk, perusahaan menerapkan budaya $C A R E$ yang bertujuan untuk membangun kepercayaan dan kesadaran konsumen. Perusahaan ini juga melakukan kegiatan positif yang bersifat komersial dan non-komersial, baik itu mencakup penjualan maupun prestasi yang diperoleh, seperti kegiatan sosial yang berdampak ke masyarakat.

Kedua, berhubungan dengan komunitas. Perusahaan selalu menggandeng orang ketiga untuk bekerjasama dalam melakukan kegiatan sosial. Pentingnya mempunyai komunitas yaitu ketika ada berita baru mengenai perusahaan, dapat langsung dibagikan kepada komunitas tersebut dan akan menghasilkan timbal balik yang bagus, serta berita tersebut menjadi tersebar luas. Timbal balik yang diberikan dapat mewujudkan citra yang positif terhadap perusahaan.

Ketiga, berhubungan dengan pemerintah. Perusahaan selalu mendukung setiap kegiatan sosial yang dilakukan oleh pemerintah dan juga perusahaan ini tidak pernah melanggar peraturan yang ditetapkan. Pemerintah mengapresiasi dengan memberi subsidi jahe untuk seluruh karyawan di perusahaan ini dan memberikan layanan serology test setiap sebulan sekali. 


\section{Ucapan Terima Kasih}

Peneliti mengucapkan terima kasih kepada pihak-pihak yang telah mendukung peneliti selama proses penelitian ini berlangsung hingga sampai penelitian ini dapat terbit dalam bentuk jurnal, khususnya kepada Fakultas Ilmu Komunikasi Universitas Tarumanaga.

\section{Daftar Pustaka}

Kompas.com. (20 Juni 2021). Diakses dari https://money.kompas.com/read/2020/05/10/091500226/perekonomianindonesia-pasca-pandemi-covid-19?page $=$ all.

Maryam. (2017). Strategi Marketing Public Relations Dalam Meningkatkan Jumlah Tamu Hotel Pantai Marina Bengkalis. Jom FISIP, 4(2) 3-6.

Pradnyana \& Sriwahyuni. (2014). Pengaruh Komunikasi Internal dan Komunikasi Eksternal Terhadap Kinerja Karyawan Pada PT. Pacific Express Garment Denpasar. Proseding Seminar Nasional Hasil Penelitian-Denpasar, 132-135.

Suwatno. (2018). Pengantar Public Relations Kontemporer. Bandung: PT. Remaja Rosdakarya. 